\title{
ANALISIS PENERAPAN PERENCANAAN PAJAK PENGHASILAN BADAN GUNA MEMINIMALKAN PEMBAYARAN PAJAK PENGHASILAN BADAN PADA PT. BUMI SARANA BETON
}

\author{
Andi Rustam ${ }^{1}$ Mira $^{2}$ Azwar $^{3}$ Ika Sartika \\ Universitas Muhammadiyah Makassar \\ e-mail: andirust99@gmail.com
}

\begin{abstract}
Research is done with the aim to know how to apply the tax planning conducted by PT Bumi Sarana Beton to minimize the burden of the company's income tax. In this study, the literature and observations review was by conducting research on the field through live interviews and data retrieval, related documents from the company as well as the use of books, and internet media. The data obtained in the analysis using a descriptive analysis is to exercise data of the commercial financial statements and the existing fiscal reports. The results showed that the application of tax planning by the company has been in accordance with the prevailing tax laws and with the implementation of taxation planning hence the saving of income tax expenses amounted to Rp 133,456,401.
\end{abstract}

Key words: Tax planning, body income tax, tax payable, tax savings

\begin{abstract}
Abstrak
Penelitian ini dilakukan dengan tujuan untuk mengetahui bagaimana penerapan perencanaan pajak yang dilakukan oleh PT. Bumi Sarana Beton untuk meminimalkan beban pajak penghasilan perusahaan. Dalam penelitian ini menggunakan tinjauan kepustakaan dan observasi yaitu dengan melakukan penelitian di lapangan melalui wawancara langsung dan pengambilan data, dokumen-dokumen yang berkaitan dari perusahaan serta menelah buku-buku, dan media internet. Data yang diperoleh di analisis dengan menggunakan analisis deskriptif yaitu dengan mengelolah data-data laporan keuangan komersial dan laporan fiskal yang ada. Hasil penelitian menunjukkan bahwa penerapan perencanaan pajak oleh perusahaan telah sesuai dengan undangundang perpajakan yang berlaku dan dengan diterapkanya perencanaan pajak maka terjadi penghematan beban pajak penghasilan sebesar Rp 133.456.401.
\end{abstract}

Kata Kunci: Perencanaan Pajak, Pajak Penghasilan Badan, Beban Pajak Terutang, Penghematan Pajak 


\section{PENDAhUluan}

Pada hakekatnya perpajakan di Indonesia di tetapkan berdasarkan undang-undang, hal ini merupakan pencerminan bagian dari pelaksanaan tonggak demokrasi dalam hidup berbangsa dan bernegara. Dalam hubungan ini merupakan suatu realita negara yang merdeka dan berdaulat. Sesuai perjalanan sejarah perpajakan nasional di Indonesia, tak dapat dipungkiri bahwa dalam penyusunan kerangka acuan perubahan undang-undang dan peraturan perpajakan sebagian besar bersumber dari sistem perpajakan warisan kolonial penjajah, terutama ketika negara Republik Indonesia baru terbentuk. Dalam beberapa dekade terakhir ini perubahan tersebut telah banyak mengalami perubahan yang bersumber dari sistem perpajakan negara lain.

Pajak adalah salah satu alat yang digunakan pemerintah didalam mencapai tujuan untuk mendapatkan penerimaan baik yang bersifat langsung maupun tidak langsung dari masyarakat, untuk itu diperlukan adanya kesadaran dari masyarakat akan kewajiban pajaknya karena pajak yang dikumpul digunakan untuk kepentingan dan membiayai pengeluaran rutin serta pembangunan sosial dan ekonomi masyarakat. Pajak merupakan fenomena umum sebagai sumber penerimaan negara yang berlaku di berbagai negara. Tiap negara membuat aturan dan dalam mengenakkan dan memungut pajak di negaranya. Bagi Indonesia, penerimaan pajak sangat besar perannya dalam mengamankan anggaran negara dalam APBN setiap tahun. Kondisi itu tercapai ketika harga minyak bumi berfluktuasi di pasar internasional dalam kurun waktu yang relatif panjang pada awal dekade 1980-an.

\section{TINJUAN PUSTAKA}

\section{Pajak Penghasilan}

Menurut Waluyo (2006) : "pajak penghasilan adalah pajak yang dikenakan terhadap subjek pajak berkenaan dengan penghasilan yang diterima atau yang diperolehnya dalam tahun pajak." Menurut ketentuan pajak, pajak penghasilan merupakan jenis pajak subjektif yang kewajiban pajaknya melekat pada subjek pajak yang bersangkutan, artinya pajak tersebut dimaksudkan untuk tidak dilimpahkan kepada subjek pajak lainya. Oleh karena itu dalam rangka memberikan kepastian hukum, penentuan saat mulai dan berakhirnya kewajiban pajak subjektif yang penting.

\section{Perencanaan Pajak}

Perencanaan pajak adalah langkah awal dalam menajemen pajak. Pada tahap ini dilakukan pengumpulan dan penelitian terhadap peraturan perpajakan dengan maksud dapat diseleksi jenis tindakan penghematan pajak yang akan dilakukan. Menurut Zain (2003) perencanaan pajak adalah merupakan tindakan struktural yang terkait dengan kondisi konsekuensi potensi pajaknya, yang tekanannya kepada pengadilan setiap transaksi yang ada konsekuensi pajaknya, tujuannya adalah bagaimana pengendalian tersebut dapat mengefisienkan jumlah pajaknya yang akan di transfer ke pemerintah, melalui apa yang disebut penghindaran pajak (tax avoidance) yang merupakan perbuatan legal yang masih dalam ruang lingkup peraturan perundang-undangan pajak dan bukan penyelundupan pajak.

\section{Tahapan Dalam Membuat Perencanaan Pajak}

Dalam arus globalisasi dan tingkat persaingan yang semakin tinggi, seorang manajer dalam membuat suatu perencanaan pajak sebagaimana strategi perencanaan perusahaan secara keseluruhan harus memperhitungkan adanya kegiatan yang bersifat lokal maupun internasional. Agar perencanaan pajak dapat berhasil sesuai dengan harapan, maka rencana itu seharusnya dilakukan melalui berbagai urutan tahap-tahap berikut ini

a. Menganalisis informasi yang ada.

b. Membuat satu model atau lebih rencana kemungkinan besarnya pajak.

c. Mengevaluasi pelaksanaan rencana pajak.

d. Mencari kelemahan dan kemudian memperbaiki kembali rencana pajak.

\section{Manfaat Perencanaan Pajak}

Tax planning merupakan bagian dari manajemen memiliki beberapa manfaat yang gi perusahaan yang melaksanakan kegiatan usaha dalam mencapai laba maksimum.

Ada 4 hal yang penting diambil sebagai keuntungan dalam perencanaan pajak yaitu:

a. Penghematan kas keluar, pajak dianggap sebagai usur biaya yang dapat diefisienkan.

b. Mengatur aliran kas, karena dengan perencanaan pajak yang dikelola secara tepat 
perusahaan dapat menyusun anggaran kas lebih akurat mengestimasi kebutuhan kas terhadap pajak.

c. Menentukan waktu pembayaran, sehingga tidak terlalu awal atau terlambat yang mengakibatkan dikenakannya denda atau sanksi.

d. Membuat data-data terbaru untuk mengaupdate peraturan perpajakan.

\section{METODE}

Penelitian ini dilakukan pada PT Bumi Sarana Beton yang merupakan salah satu anak perusahaan PT Hadji Kalla dimana sasaran utama perusahaan ini adalah memproduksi Beton Siap Pakai (Ready Mix). Pengambilan data dilakukan di kantor pusat PT. Bumi Sarana Beton yang bertempat di Wisma Kalla Lantai 10 di Jl. Dr. Sam Ratulangi No. 8 Makassar.

Metode analisis yang digunakan dalam penelitian ini adalah metode analisis deskriptif. Adapun langka-langkanya adalah sebagai berikut.

a. Pengumpulan data yang diperlukan antara lain laporan laba/rugi komersial, laporan laba/rugi fiskal, neraca dan kebijakankebijakan perusahaan.

b. Melakukan pengolaan data yang diperoleh dari perusahaan dengan memahami prosedur dan kebijakan yang berlaku di perusahaan terkait dengan perpajakan dan memeriksa sumber-sumber penghasilan perusahaan.

c. Mentukan besarnya laba kena pajak denagn melakukan rekonsiliasi laporan keuangan komersial dan laporan keuangan fiskal.

d. Menentukan besarnya pajak pengahasilan apabila perusahaan menerapkan tax palanning dalam pengelolaan keuangan dengan memaksimalakan biaya fiskal dan meminimalakan biaya yang tidak diperkenankan sebagai pengurang.

\section{HASIL DAN PEMBAHASAN}

\section{Perencanaan Pajak PT. Bumi Sarana Beton}

Kebijakan akuntansi perusahaan dalam menjalankan kegiatan operasinya, antara lain.

a. Laporan keuangan disusun berdasarkan konsep harga peolehan (historical cost) menggunakan acrual basis, kecuali untuk laporan arus kas.

b. Laporan arus kas disusun dengan menggunakan metode langsung (direct method) dengan mengelompokkan arus kas dalam aktivitas operasi, investasi, dan pendanaan.

c. Metode penelitian persediaan menggunakan metode rata-rata bergerak.

d. Aset tetap dinyatakan sebesar harga perolehan (pengakuan awal) setelah dikurangi akumulasi penyusutan dan akumulasi penurunan aset tetap. Setelah pengakuan awal, aset tetap diukur dengan model biaya (cost model)

e. Aset tetap lainya disusutkan dengan menggunakan metode garis lurus berdasarkan estimasi manfaat masingmasing aset tetap.

\section{Laporan Keuangan Perusahaan}

Bagian ini akan menampikan data yang diperoleh dari PT. Bumi Sarana Beton. Data yang akan ditampilkan adalah laporan keuangan yang dibuat oleh perusahaan yang terdiri dari Laporan Laba/Rugi Komersial dan laporan Posisi Keuangan yang hubungan dengan tahun 2014.

Tabel 1 PT. Bumi Sarana Beton Laporan Laba Rugi Komprehensip Untuk Tahun yang Berakhir pada Tanggal 31 Desember 2014 (Dinyatakan dalam Rupiah)

\begin{tabular}{ll}
\hline Pendapatan Bersih & 161.654 .893 .359 \\
\hline Beban Pokok & 136.070 .861 .84 \\
\hline Laba Kotor & $\mathbf{2 5 . 5 8 4 . 0 3 1 . 5 1 2}$ \\
\hline Beban Usaha & \\
\hline Pemasaran Dan Penjualan & 3.089 .044 .413 \\
\hline Administrasi Dan Umum & 13.196 .516 .610 \\
\hline Total Beban Usaha & $\mathbf{1 6 . 2 8 5 . 5 6 1 . 0 2 3}$ \\
\hline Pendapatan (Beban) & - \\
\hline Lain-Lain & 256.100 .440 \\
\hline Pendapatan Lain-Lain & $\mathbf{( 7 9 7 . 8 3 8 . 3 0 9 )}$ \\
\hline Beban Lain-Lain & $\mathbf{5 4 1 . 7 3 7 . 8 6 9}$ \\
\hline Total Pendapatan (Beban) Lain-Lain Laba Sebelum (Beban)/Penghasilan & $\mathbf{8 . 7 5 6 . 7 3 2 . 6 2 0}$ \\
\hline Pendapatan Dan Pajak Penghasilan &
\end{tabular}




\begin{tabular}{ll}
\hline Penghasilan Keuangan & 70.346 .899 \\
\hline Beban Keuangan & 4.756 .927 .293 \\
\hline Total Pendapatan (Beban) Keuangan & $\mathbf{4 . 6 8 6 . 5 8 0 . 3 9 4}$ \\
\hline Laba Sebelum Pajak Penghasilan & $\mathbf{4 0 7 0 1 5 2 2 2 6}$ \\
\hline
\end{tabular}

Sumber: PT Bumi Saran Beton

Tabel 2. PT Bumi Sarana Beton Laporan Posisi Keuangan Desember 2014 (Disajikan Dalam Rupiah Penuh, Kecuali Dinyatakan Lain)

\begin{tabular}{ll}
\hline Jumlah Aset Lancar & 73.968 .251 .158 \\
\hline Jumlah Aset Tidak Lancar & 124.242 .472 .314 \\
\hline Jumlah Aset & 198.210 .723 .472 \\
\hline Jumlah Liabilitas Jangka Pendek & 127.201 .353 .360 \\
\hline Jumla Liabilitas Jangka Panjang & 28.562 .352 .220 \\
\hline Jumlah Ekuitas & 44.438 .017 .892 \\
\hline Jumlah Liabilitas Dan Ekuitas & 198.210 .723 .472 \\
\hline Sumber: PT Bumi Saran Beton &
\end{tabular}

\section{Penghasilan Kena Pajak}

Penghasilan Kena Pajak atau Laba Fiskal disususn setelah dilakukannya koreksi dan tidak disajikan secara terpisah oleh perusahaan. Koreksi fikal dalam penentuan pajak penghasilan terjadi karena adanya perbedaan perlakuan/pengakuan penghasilan maupun biaya atau yang biasa disebut beda tetap dan beda waktu sehingga menyebabkan laba yang dihitung perusahaan dan laba yang dihitung berdasarkan aturan perpajakan berbeda.

\section{Koreksi Fiskal}

Pada PT Bumi Sarana Beton, penelitian menentukan adanya perbedaan waktu sehingga diperlukan koreksi fiskal baik positif maupun negatif. Berikut ini peneliti menyajikan koreksi fiskal yang terjadi pada perusahaan sehingga perhitungan pajak untuk periode 2014.

Tabel 3. Perhitungan Neto Fiskal PT Bumi Sarana Beton Tahun Pajak 2014.

\begin{tabular}{ll}
\hline Penyesuaian Fiskal Positif & Laba Komersial \\
\hline Biaya yang dibebankan/dikeluarkan untuk kepentingan pemegang saham, sekutu atau anggota & $\mathbf{4 . 0 7 0 . 1 5 2 . 2 2 6}$ \\
\hline Pembentukan atau pemupukan dana cadangan & - \\
\hline $\begin{array}{l}\text { Jumlah yang melebihi kewajaran yang dibayarkan kepada pemegang saham/ pihak yang } \\
\text { mempunyai hubugan istimewa sehubungan dengan pekerjaan }\end{array}$ & - \\
\hline Harta yang dihibahkan, bantuan atau sumbangan & - \\
\hline Pajak Penghasilan & 108.955 .000 \\
\hline $\begin{array}{l}\text { Gaji yang dibayarkan kepada anggota persekutuan, firma, atau CV yang modalnya tidak terbagi } \\
\text { atas saham }\end{array}$ & - \\
\hline Sanksi administrasi & - \\
\hline Selisih penyusutan komersial diatas penyusutan fiskal & - \\
\hline Selisih amrtisasi komersial diatas penyusutan fiskal & - \\
\hline Biaya yang ditangguhkan pengakuanya & - \\
\hline Penyesuaian fiskal positif lainya & - \\
\hline JUMLAH & 1.653 .049 .039 \\
\hline Penyesuaian Fiskal Negatif & $\mathbf{1 . 7 6 2 . 0 0 4 . 0 3 9}$ \\
\hline Selisih penyusutan komersial dibawah penyusutan & 414.455 .460 \\
fiskal & - \\
\hline Selisih amortisasi komersial dibawah penyusutan fiskal & 2.980 .803 .278 \\
\hline Penghasilan yang ditangguhkan pengakuanya & 70.346 .899 \\
\hline Pendapatan yag dikenakan PPh Final & - \\
\hline Pendapatan bunga & - \\
\hline Penyesuaian fiskal negatif lainya & $\mathbf{3 . 4 6 5 . 6 0 5 . 6 3 7}$ \\
\hline JUMLAH & $\mathbf{2 . 3 6 6 . 5 5 0 . 6 2 8}$ \\
\hline lABA KENA PAJAK & 591.637 .657 \\
\hline Pajak penghasilan terutang sesuai UU PPh Pasal 17 28\% X Rp 2.336.550.628
\end{tabular}


Dari data yang diperoleh dari perusahaan dapat dilihat laba tahun berjalan sebelum pajak menurut perusahaan (Laporan Keuangan Komersial) sebesar Rp 4.070.152.226 sementara penghasilan kena pajak setelah penerapan penyesuaian fiskal diperoleh jumlah laba sebesar Rp 2.366.550.628.

\section{Penerapan Perencanaan Pajak Pada PT Bumi Sarana Beton}

Perencanaan pajak yang dapat dilakukan pada PT Bumi Sarana Beton guna menghemat pembayaran pajak kepada negara yaitu dengan mengubah metode penghitungan PPh Pasal 21 karyawan yang sebelumnya menggunakan metode Net Method dimana perusahaan (pemberi kerja) awalnya menanggung PPh Pasal 21 dan tidak dimasukkan ke dalam unsur penghasilan karyawan diubah menjadi metode gross up dimana pembayaran PPh Pasal 21 oleh perusahaan diberikan dalam bentuk tujuan pajak dan dapat dikurangkan dari penghasilan bruto sehingga otomatis mengurangi penghasilan kena pajak perusahaan

\section{KESIMPULAN DAN SARAN}

\section{Kesimpulan}

Penerapan perencanaan pajak yang dilakukan PT Bumi Sarana Beton untuk meminimalkan beban pajak penghasilan badan, perusahaan memiliki kebijakan-kebijakan akuntansi yang dijadikan acuan. Selain itu perusahaan juga melakukan bebarapa langka seperti, memaksimalkan biaya fiskal dan meminimalkan biaya yang tidak diperkenankan sebagai pengurang, perusahaan telah menempuh opsi fiskal yang dapat meminimalkan pajaknya sehingga peneliti tidak menemukan opsi fiskal yang lain yang dapat menghemat pajaknya. Dari analisis yang dilakuakan terhadap penerapan perencanaan pajak yang diterapkan oleh perusahaan dengan undang-undang perpajakan yang berlaku ternyata perusahaan tidak melakukan pelanggaran dan masih mengikuti semua peraturan yang berlaku.

\section{Saran}

Dari hasil kegiatan penelitian yang dilakukan, peneliti menyarankan agar PT Bumi Sarana Beton harus senantiasa mengikuti perkembangan peraturanperaturan perpajakan atau isu-isu yang terkait dengan perpajakan agar dapat melakukan perencanaan pajak dengan efektif di masa yang akan datang. Dengan demikian, dengan adanya perencanaan pajak maka tingkat kepatuhan PT Bumi Sarana Beton selaku wajib pajak Badan menjadi semakin baik.

\section{REFERENSI}

Anastasia Diana, dan Lilis Setiawati, 2009, Perpajakan Indonesia, Andi, Yogyakarta.

Ananda dkk, 2015, pengaruh sosialisasi perpajakan, tarif pajak, dan pemahaman perpajakan terhadap kepatuhan wajib pajak, jurnal perpajakan (JEJAK) Vol.6 No. 2

Chaezahrani, 2016, penerapan perencanaan pajak (tax planning) atas pemotongan pajak penghasilan pasal 21 pegawai tetap PT. RSA dalam meminimalkan pajak penghasilan badan.

Dewi dan Setiawati, 2011, analisis dampak perubahan UU pajak penghasilan terhadap besarnya pajak penghasilan pada PT. JAJ, Binus Business Review Vol.2 No.2.

Dwiyanti dan Sukartha, 2013, pengaruh perubahan tarif pajak penghasilan badan tahun 2010 pada manajemen laba, EJurnal Akuntansi Universitas Udayana 5.1: 33-52.

Ikatan Akuntan Indonesia, 1999. Standar Akuntansi Keuangan. PSAK No. 17, Cetakan Keempat, Buku Satu, Penerbit Salemba Empat, Jakarta.

Ifadhoh dan Amanah, 2013, implementasi Tax Planning pajak penghasilan badan PT. Indojaya Mandiri, Jurnal ilmu dan Riset akuntansi Vol.2 No.10.

Kalangi, 2014, perencanaan pajak penghasilan pasal 21 pada Hotel Sahid Khawanua Manado, jurnal EMBA Vol. 4 No. 2.

Lumbantoruan, Shopar, 2005, Akuntansi Pajak, Gramedia Widiasarana. Jakarta

Muaja dkk, 2015, analisis penerapan perencanaan pajak pada wajib pajak badan di PT. Elsadai Servo Cons, Jurnal Emba Vol.3 No.4, Hal. 82-91.

Muljono, Djoko 2009, TAX PLANNING Menyiasati Pajak dengan Bijak.Yogyakarta: ANDI.

Mardiasmo. 2011, Perpajakan Edisi Revisi 2011, Andi, Yogyakarta.

Munawir S. 2002, Perpajakan, Edisi Revisi, Liberty, Yogyakarta 
Pohan, CA 2011, Optimazing Corporate Tax Management, Bumi Aksara, Jakarta.

Resmi, Sitti 2009, Perpajakan: Teori dan Kasus, Jakarta: Salemba Empat.

Rahayu, Siti Kurnia 2009, Perpajakan Indonesia, Graha Ilmu, Yogyakarta

Salihuta dan Noviari, 2013, penerapan perencanaan pajak penghasilan pasal 21 sebagai strategi penghematan pembayaran pajak, E-Jurnal akuntansi universitas udayana 5.1: 231-250.

Sugeng, 2011, pengaruh perencanaan pajak terhadap efisiensi beban pajak penghasilan, jurnal riset akuntansi dan bisnis Vol.11 No.2.
Suandy, Erly, 2006, Perpajakan, Edisi Pertama, Salemba Empat, Jakarta.

Soemahamidjadja Soeparman, "Pengantar Ilmu Hukum Pajak". (2002:5)

Waluyo, 2006. Perpajakan Indonesia: Pembahasan Sesuai dengan Ketentuan Perundang-undangan Perpajakan dan Aturan Pelaksanaan Perpajakan Terbaru jakarta: Salemba Empat.

Wulandari, 2015, faktor-faktor yang mempengaruhi penerimaan pajak penghasilan pada KKP Pratama, Perbanas Review Vol. 1 No. 1.

Zain, Muhammad 2003, Manajemen Perpajakan, Edisi Pertama, Salemba Empat, Jakarta 